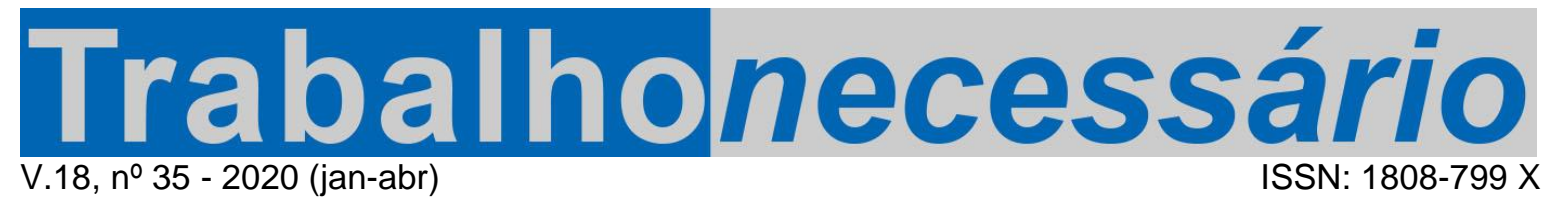

DOI: https://doi.org/10.22409/tn.v18i35.40497

\title{
A HISTORICIDADE DA EDUCAÇÃO PROFISSIONAL: O PORTAL DA MEMÓRIA DO IFRN ${ }^{1}$
}

\author{
Olívia Morais de Medeiros Neta² \\ Francisco das Chagas Silva Souza ${ }^{3}$
}

\section{Resumo}

Neste artigo, analisamos o Portal da Memória do Instituto Federal de Educação, Ciência e Tecnologia do Rio Grande do Norte (IFRN). A metodologia constou de um levantamento dos tipos de elementos presentes nesse Portal. Verificamos que o conteúdo disponibilizado no Portal pode ser entendido como fontes para temas de estudo em história da Educação Profissional, a saber: história das instituições, cultura escolar, currículo, cultura material escolar e sociabilidades. Destacamos que as fontes presentes nesse Portal não falam per se, mas trazem a possibilidade de acesso às dimensões da história e da memória da educação institucional, possibilitando a democratização da memória relativa à historicidade do IFRN.

Palavras-chave: Educação Profissional. História da educação. Memória. Fonte histórica.

\section{HISTORICIDAD DE LA EDUCACIÓN PROFESIONAL: EL PORTAL DE MEMORIA DEL IFRN}

\section{Resumen}

En este artículo, analizamos el Portal de Memoria del Instituto Federal de Educación, Ciencia y Tecnología de Rio Grande do Norte (IFRN). La metodología consistió en una encuesta de los tipos de elementos presentes en este Portal. Descubrimos que el contenido disponible en el Portal puede entenderse como fuentes de materias de estudio en la historia de la Educación Vocacional, a saber: historia de las instituciones, cultura escolar, plan de estudios, cultura del material escolar y sociabilidad. Hacemos hincapié en que las fuentes presentes en este Portal no hablan en sí, sino que brindan la posibilidad de acceder a las dimensiones de la historia y la memoria de la educación institucional, lo que permite la democratización de la memoria en relación con la historicidad de la IFRN. Palabras clave: Educación profesional. Historia de la educación. Memoria. Fuente histórica.

\section{THE HISTORICITY OF PROFESSIONAL EDUCATION: THE IFRN MEMORY PORTAL}

\section{Abstract}

In this article, we analyze the Memory Portal of the Federal Institute of Education, Science and Technology of Rio Grande do Norte (IFRN). The methodology consisted of a survey of the types of elements present in this Portal. We found that the content available on the Portal can be understood as sources for studying subjects in the history of Vocational Education, namely: history of institutions, school culture, curriculum, school material culture and sociability. We emphasize that the sources present in this Portal do not speak per se, but they have the possibility

\footnotetext{
1 Artigo recebido em 15/09/2019. Primeira Avaliação em 07/10/2019. Segunda Avaliação em 08/10/2019. Aprovado em 08/11/2019. Publicado em 23/01/2020.

2 Possui graduação em História (Licenciatura e Bacharelado), mestrado em História e doutorado em Educação pela Universidade Federal do Rio Grande do Norte. E-mail: olivianeta@gmail.com Orcid: https://orcid.org/0000-0002-4217-2914

${ }^{3}$ Doutor em Educação (UFRN), professor do Programa de Pós-Graduação em Educação Profissional (IFRN), do Programa de Pós-Graduação em Educação Profissional e Tecnológica (ProfEPT - Mestrado Profissional em Rede Nacional) e do Programa de Pós-Graduação em Ensino (UERN/IFRN/UFERSA). E-mail: chagas.souza@ifrn.edu.br Orcid: https://orcid.org/0000-0002-9721-9812
} 
of accessing to the dimensions of history and memory of institutional education. Therefore, it enables the democratization of the memory related to the historicity of IFRN.

Keywords: Professional Education. History of education. Memory. Historical sources.

\section{Introdução}

Em 23 de setembro de 1909, o então Presidente da República do Brasil, Nilo Peçanha, criou 19 Escolas de Aprendizes Artífices, uma em cada estado da federação. Em 2009, o Instituto Federal de Educação, Ciência e Tecnologia do Rio Grande do Norte (IFRN) comemorava, junto com outras instituições federais de Educação Profissional, seu primeiro centenário.

No IFRN, em meio às festividades comemorativas do seu centenário, uma das ações mais representativas foi a criação do Portal da Memória, cuja finalidade era apresentar ao público interno e externo a história dessa instituição de ensino, destacando os principais acontecimentos de sua trajetória por meio de cronologia, fotografias e depoimentos de sujeitos que fizeram parte do corpo escolar em temporalidades distintas. Portanto, na "festa do centenário", como ficou conhecida a programação do aniversário, não só interessava a celebração, mas a guarda da memória institucional com o uso das tecnologias digitais.

Nosso objetivo, neste artigo, é analisar o Portal da Memória do Instituto Federal de Educação, Ciência e Tecnologia do Rio Grande do Norte (IFRN) considerando o seu conteúdo e o seu caráter de lugar de memória institucional à Educação Profissional. Por isso, partimos das seguintes questões de investigação: o que foi selecionado para ser arquivado no Portal como marcas da memória da Educação Profissional da instituição? Que imagem de si essa instituição visa criar por meio do Portal?

Para responder a essas questões, realizamos um levantamento das narrativas visuais (fotografias digitalizadas, depoimentos orais) e escritas arquivadas no Portal da Memória do IFRN para, em seguida, analisar como esse arquivo se converteu em um lugar de memória na perspectiva de Nora (1993). Portanto, com base nesses pressupostos, dividimos esse texto em duas partes. Na primeira, descrevemos o conteúdo presente do Portal e, em seguida, com base nos estudos sobre memória, discutimos como ele foi construído para ser um lugar de memória da instituição de ensino. 


\section{Mapeando o Portal da Memória do IFRN}

Como nos ensina Halbwachs (2006), são as condições sociais do presente que possibilitam as manifestações da memória. Assim, não é possível compreendermos o porquê da existência do Portal da Memória do IFRN sem considerarmos duas datas: 23 de setembro de 1909 e 29 de dezembro de 2008. Na primeira, o Presidente da República Nilo Peçanha criou, por meio do Decreto №. 7.566, 19 Escolas de Aprendizes Artífices, dando início às políticas do Governo Federal brasileiro no ensino de ofícios (BRASIL, 1909). Na segunda, o Presidente Luís Inácio Lula da Silva, por meio da Lei nº. 11.892, instituiu a Rede Federal de Educação Profissional, Científica e Tecnológica, e criou 38 Institutos Federais de Educação, Ciência e Tecnologia (IF), trazendo uma nova institucionalidade para as antigas Escolas de Aprendizes Artífices que, ao longo do século XX, mudaram várias vezes de denominação (BRASIL, 2008). Portanto, essas duas importantes datas não apenas destacam o centenário dessa instituição de Educação Profissional, mas também são importantes marcos que alteraram profundamente a história dessa modalidade de ensino no Rio Grande do Norte e no Brasil.

Todavia, como é de se supor, o aniversário de um século não poderia ficar sem uma celebração. Partindo desse argumento, o IFRN, à época Centro Federal de Educação, Ciência e Tecnologia do Rio Grande do Norte (CEFET-RN), deu início, já em 2006, a um projeto intitulado "A caminho do centenário", cuja finalidade era apresentar às comunidades interna e externa a história de seus cem anos, destacando os principais acontecimentos que marcaram sua trajetória. Como parte desse projeto, foi criado o Portal da Memória, planejado para ser um museu virtual, por meio do qual os seus visitantes têm acesso a fatos que marcaram o funcionamento dessa instituição ao longo do século $X X$.

O Portal da Memória do IFRN está dividido em sete seções:

1. Uma agenda com atividades ocorridas no mês de setembro de 2009 em comemoração ao centenário: eventos esportivos e culturais, encontro de ex-alunos, ato ecumênico, apresentações artísticas, sessão na câmara municipal de Natal, exposições técnicas e culturais nos campi Mossoró e Currais Novos. 
2. Uma cronologia com imagens fotográficas da instituição: fachadas dos prédios onde funcionou ao longo da sua história, solenidades, criação de cursos técnicos.

3. Na seção denominada "atos e fatos" estão disponibilizadas decisões administrativas da gestão, construções de prédios, fotografias de eventos esportivos e da banda de música, além de outros registros de acontecimentos que marcaram a sua história.

4. O quarto item é composto por depoimentos orais, gravados em entrevistas feitas com ex-diretores, professores aposentados e ex-alunos da instituição, alguns destes últimos hoje servidores do IFRN, alguns aposentados.

5. Na quinta seção encontramos depoimentos escritos por servidores atuais e aposentados e de ex-alunos relatando fatos que marcaram as suas histórias de vida e que tem relação com essa instituição de Educação Profissional.

6. No item ex-diretores, encontramos fotografias e dados biográficos de todos os diretores que passaram pela gestão do IFRN desde quando este era denominado Escola de Aprendizes Artífices de Natal.

7. Na sétima e última parte, encontramos uma relação de eventos que ocorreram na instituição e que se relacionam com a festa do centenário, mas também que fazem de sua história do tempo presente.

Por conseguinte, é possível destacar a importância deste arquivo virtual para o campo da História da Educação Profissional no Brasil. Quanto a esse tema, ressalta-se que, embora se perceba muitos esforços no incentivo aos estudos no campo da História da Educação brasileira, destes, segundo afirma Cunha (2000), poucos foram dedicados à História da Educação Profissional do Brasil. Há quase duas décadas, esse pesquisador considerava que a produção acadêmica, nesse campo, apresentava "espaços vazios":

Esse "espaço vazio" se explica, pelo menos em parte, pelo fato de que os historiadores da educação brasileira se preocupam, principalmente, com o ensino que se destina às elites políticas e ao trabalho intelectual, deixando o trabalho manual em segundo plano - atitude consistente, aliás, com sua própria formação (CUNHA, 2000, p. 89).

A produção acadêmica deu grande ênfase à educação denominada propedêutica, destinada às elites, em detrimento da educação profissional. Essa negação ao ensino profissional pode encontrar explicação na íntima relação deste 
com a marginalização a qual foram relegados os trabalhos manuais, ocupados por escravos, índios e homens livres pobres no início da história do Brasil.

Quinze anos depois de Cunha fazer esse comentário, Ciavatta também ressaltou esse problema na produção historiográfica no Brasil:

[...] à exceção de poucos, raros são os historiadores que se dedicam ao estudo da Educação [...] estudam o Trabalho em suas diversas formas e temporalidades, mas não a relação entre o mundo do trabalho e a educação ou a escola. Da outra parte, no Brasil, são ainda mais raros os historiadores de Educação que se dedicam à pesquisa envolvendo o trabalho, a divisão social do trabalho e a estrutura das classes sociais. Prevalecem os estudos com base na história cultural que, na maioria das vezes, são interessantes, mas se dedicam a cuidadosas e documentadas descrições (CIAVATTA, 2015, p. 47).

O conteúdo do Portal da Memória do IFRN contribui para a historicidade da Educação Profissional no Brasil, mais especificamente para uma abordagem acerca da história das instituições escolares, um dos temas mais recorrentes nos eventos acadêmicos na área da educação.

Os estudos de Nosella e Buffa (2013), Magalhães (1996, 2004), Saviani (2007, 2013), Sanfelice (2006), dentre outros pesquisadores da história das instituições escolares, salientam que estas têm uma temporalidade e não podem ser estudadas afastadas de um contexto maior, visto que estão associadas a projeto de político e de sociedade. Sendo assim:

Compreender e explicar a existência histórica de uma instituição educativa é, sem deixar de integrá-la na realidade mais ampla que é o sistema educativo, contextualizá-la, implicando-a no quadro de evolução de uma comunidade e de uma região, é por fim sistematizar e (re) escrever-lhe o itinerário de vida na sua multidimensionalidade, conferindo um sentido histórico. (MAGALHÃES, 1996, p. 2).

Também é elucidativa a análise feita por Sanfelice (2006, p. 23):

As instituições escolares têm também uma origem quase sempre muito peculiar. Os motivos pelos quais uma unidade escolar passa a existir são os mais diferenciados. Às vezes a unidade escolar surge como uma decorrência da política educacional em prática. Mas nem sempre. Em outras situações a unidade escolar somente se viabiliza pela conquista de movimentos sociais mobilizados, ou pela iniciativa de grupos confeccionais ou de empresários. A origem de cada instituição escolar, quando decifrada, costuma nos oferecer várias surpresas. 
Com base nas observações de Magalhães (1996) e de Sanfelice (2006), podemos afirmar que o Portal da Memória e as fontes a ele associadas possibilitam pesquisas no campo da história das instituições escolares considerando os seguintes enfoques: os processos de criação e o ciclo de vida de uma instituição educativa, criada em 1909 com vistas a oferta do ensino de ofícios; a configuração e as mudanças ocorridas na arquitetura do prédio escolar; os processos de conservação e mudança do perfil dos docentes e discentes; as formas de configuração e transformação do saber veiculado nestas instituições de ensino; as concepções de Educação Profissional presentes nos discursos de gestores, servidores e ex-alunos, dentre outros temas.

O Portal também se preocupa em registrar, por meio de imagens fotográficas e relatos orais gravados em vídeos, algumas práticas do cotidiano da instituição que diz respeito à cultura escolar, categoria de análise definida por Julia (2001, p. 10) como:

[...] um conjunto de normas que definem conhecimentos a ensinar e condutas a inculcar, e um conjunto de práticas que permitem a transmissão desses conhecimentos e a incorporação desses comportamentos; normas e práticas coordenadas a finalidades que podem variar segundo épocas (finalidades religiosas, sociopolíticas ou simplesmente de socialização). (Grifos do autor).

A cultura escolar como categoria de análise tem, atualmente, lugar privilegiado nos referenciais teórico-metodológicos de pesquisas no campo da História da Educação e em grupos de trabalho ou eixos temáticos de congressos desse mesmo campo. De acordo com Faria Filho e Vidal (2003, p. 10) a utilização da cultura escolar contribuiu para "adentrar a 'caixa preta' da sala de aula", possibilitando "[...] desnaturalizar a instituição escolar, historicizando a própria institucionalização da educação escolar e discutindo de forma articulada os tempos, espaços, sujeitos, materiais e conhecimentos envolvidos naquilo que alguns têm chamado de processo de escolarização da sociedade".

As memórias a respeito das normas, das finalidades que regiam a escola, da profissionalização do trabalho do educador, dos conteúdos ensinados e das práticas escolares, podem ser encontradas na seção "Mensagens". Nela, depoimentos como o de José do Nascimento, ex-aluno da então Escola Industrial de Natal (EIN), de 1945 
a 1948, enaltecem a função social dessa instituição. O entrevistado ressalta que a EIN "[...] era a grande esperança [...]" para os alunos pobres, pois a formação técnica oportunizaria a inserção no mercado de trabalho bem como uma ampla formação para a vida.

Também na seção "Mensagens", Walter Medeiros, ex-aluno do Ginásio Industrial e do Curso Técnico em Mineração, no final da década de 1960, lembra da cor caqui da farda, da disciplina escolar, do trabalho nas oficinas e das aulas de Educação Física. Nessa mesma perspectiva memorialística, Severino do Ramo, exaluno da Escola Industrial de Natal e, posteriormente, professor da instituição, entre 1965 e 1995, narrou suas experiências sobre o cotidiano escolar e como ocorriam as práticas educativas no Centro Lítero-Recreativo Nilo Peçanha. O Centro foi fundado em 1940, na Escola Industrial de Natal e durante décadas reuniu alunos com fins de leitura e discussão de textos, realização de eventos cívicos e outras atividades no espaço escolar e extraescolar.

Ainda quanto à cultura escolar e às possibilidades de análise nas fontes veiculadas no Portal da Memória destacamos fontes imagéticas e orais que destacam o ensino de música na instituição em outras temporalidades - fosse o ensino do canto orfeônico, com a professora Lourdes Guilherme, ex-aluna do músico Heitor VillaLobos, na Escola Industrial de Natal, nas décadas de 1940 até o início da década de 1960; ou as apresentações do Coral da Escola Técnica Federal do Rio Grande do Norte, criado em 1975, denominado Lourdes Guilherme, em homenagem à docente de música.

Nos depoimentos orais de ex-alunos e ex-professores, as práticas esportivas são sempre rememoradas como indispensáveis à formação humana e cidadã. Dessa forma, Augusto Serrano e Ferdinando Teixeira rememoram as aulas e as competições esportivas que ocorriam nas décadas de 1970, principalmente. Sobre a prática de Educação Física, fontes escritas na seção "Depoimentos" e imagéticas, na seção "Atos e Fatos", corroboram com os comentários tecidos pelos entrevistados.

Considerando que a cultura escolar se vincula às análises de normas e práticas com vistas ao corpo profissional, aos dispositivos pedagógicos e aos modos de pensar e ler nos processos formais de escolarização, na história dessa instituição de Educação Profissional, a disciplina é temática recorrente, estando presente na memória escrita ou falada de ex-alunos, professores e dirigentes. Aqui, especificamente, realçamos o 
papel do Corpo de Vigilantes, criado nos anos de 1940, que tinha como propósito ampliar o controle sobre as atitudes e os comportamentos dos alunos.

O Corpo de Vigilantes era formado por um grupo de nove alunos titulares e três suplentes, escolhidos pelos professores, com a aprovação do diretor. Dentre os depoimentos que citam o Corpo de Vigilantes está o de Maurílio Pinto, ex-aluno da Escola Industrial de Natal, que relembra as exigências e punições referentes às práticas no interior da escola e em suas cercanias.

Por conseguinte, pode-se dizer que a criação do Portal da Memória do IFRN teve a finalidade de "resgatar" a memória, mesmo que isso não ocorra de forma pura e sem influências do presente e da posição social em que se encontram os sujeitos. Essa memória coletiva

[...] tira a sua força e sua duração por ter como base um conjunto de pessoas, são os indivíduos que se lembram, enquanto integrantes do grupo. Dessa massa de lembranças comuns, umas apoiadas nas outras, não são as mesmas que aparecerão com maior intensidade a cada um deles. De bom grado, diríamos que cada memória individual é um ponto de vista sobre a memória coletiva, que este ponto de vista muda segundo o lugar que ali ocupo e que este lugar muda segundo as relações que mantenho com outros ambientes. Não é de surpreender que nem todos tirem o mesmo partido do instrumento comum. Quando tentamos explicar essa diversidade, sempre voltamos a uma combinação de influências que são todas de natureza social (HALBWACHS, 2006, p. 69).

Importa destacar que, apesar do esforço institucional em guardar essas memórias para as gerações presentes e as do futuro, esse trabalho de arquivamento apresentou alguns problemas com que diz respeito à rigorosidade metodológica que deve assumir um pesquisador: recortes de jornais escaneados e com poucas condições de leitura, ausência de datas nas gravações dos relatos orais, fotografias sem data, legenda e autoria. Todavia, acreditamos que essas limitações não tiram desse Portal a capacidade de democratizar a memória institucional e criar representações sobre o passado do atual IFRN, nem ainda de mostrar como esse passado é recortado e construído pela comunidade acadêmica e pelo grupo gestor.

\section{O Portal da Memória do IFRN como guardião do passado da Educação Profissional}


Para Bloch (2001, p. 75), "o passado é, por definição, um dado que nada mais modificará. Mas o conhecimento do passado é uma coisa em progresso, que incessantemente se transforma e se aperfeiçoa". Entretanto, diz adiante esse historiador que "os textos ou os documentos arqueológicos, mesmo os aparentemente mais claros e mais complacentes não falam senão quando sabemos interrogá-los" (2001, p. 79).

A vida na/da escola também tem se constituído em objeto de estudo dos historiadores. Tornou-se frequente a divulgação do patrimônio educativo por meio da criação de museus em vários países, como ressalta Mogarro (2012/2013), sobretudo na primeira década do século XXI, um movimento que "exprime modalidades simultaneamente convergentes e específicas de perspectivar o patrimônio educativo e a cultura escolar" (2012/2013, p. 70). Em seu estudo, a autora faz um balanço do panorama internacional da criação e revitalização de museus da educação e dos museus pedagógicos, como também das iniciativas de salvaguarda e divulgação de coleções patrimoniais existentes nas escolas.

Linares e Alderoqui (2013) também ressaltam a expansão dos museus da educação no final do século XX e os distinguem dos museus pedagógicos do século XIX. Estes últimos "tenían un fuerte carácter prospectivo y fundante de las nuevas teorías pedagógicas, metodologías, utillaje, política y estrutura escolar a la par de la intención de construir identidades nacionales" (2013, p. 3). Já os atuais museus, "Pueden ser caracterizados como museos históricos y es discutible la intención de construir identidades nacionales, aunque para algunos sea un objetivo explícito". Além disso, diferenciam-se também quanto ao público para o qual se destinam. "Los museos pedagógicos decimonónicos estaban orientados a los maestros o a los estudiantes de magisterio. Los museos actuales, aunque plantean diferencias, se orientan hacia un público más general” (2013, p. 4). As autoras observam ainda que:

El Museo de las Escuelas es considerado un museo de última generación porque difiere en cuanto al enfoque y la forma en que el visitante interactúa con la exhibición. En este tipo de museos se promueve una participación más creativa por parte de los visitantes quienes tienen las posibilidades de elegir entre diferentes opciones de interacción (LINARES E ALDEROQUI, 2013, p. 5).

A partir do exposto, podemos afirmar que o Portal da Memória do IFRN foi idealizado e criado num cenário mais amplo. Os dados que dispõem aos seus 
visitantes não são simples lembranças relativas à comemoração de um século de história e à preocupação do IFRN com o "resgate" do passado institucional, como se pudéssemos trazer à tona acontecimentos pretéritos de maneira pura e isenta de qualquer influência pessoal. Sobre esse aspecto, não podemos deixar de lembrar Benjamin (1994) ao refletir que o narrador não está interessado em transmitir o "puro em si" da coisa narrada como uma informação ou relatório. "Ela [a narrativa] mergulha a coisa na vida do narrador para em seguida retirá-la dele. Assim se exprime na narrativa a marca do narrador, como a mão do oleiro na argila do vaso" (1994, p. 205, grifo nosso).

Contudo, se Benjamin, na primeira metade do século $\mathrm{XX}$, anunciava os riscos que os avanços da mídia traziam para a função desempenhada pelas narrativas (aconselhar e transmitir experiências), hoje, ao contrário disso, alguns estudiosos dão relevo à expansão das narrativas por outros suportes, como a mídia eletrônica. Defende-se que esta não sufocaria as narrativas orais como manifestação da memória coletiva, mas sim, conviveria com ela. Nessa direção, Santos e Santos (2012, p. 162) explicam que "O ciberespaço constitui, portanto, espaços-tempos de práticas sociais cujo objetivo não é o de inibir ou acabar com práticas anteriores. Não se trata de uma lógica excludente [...]." Dessa maneira, para essas autoras, os ambientes online e sua dinâmica possibilitam a criação de

redes sociais de docência e aprendizagem, pois permite experiências significativas de aprendizagem nos diferentes espaçostempos da cibercultura, assim, outras e novas redes educativas vão emergindo e inspirando novas práticas cotidianas" (SANTOS; SANTOS, 2012, p. 180).

Diante do exposto, o Portal da Memória, como arquivo/museu escolar digital, nasceu com o desenvolvimento das novas tecnologias da comunicação geradas pela memória eletrônica, na segunda metade do século XX. Esta, ao contrário da instabilidade e da maleabilidade da memória humana, é estável e apresenta uma grande facilidade de evocação, como afirma Le Goff (2003). Porém, para este historiador, a memória eletrônica

só age sob a ordem e segundo o programa do homem [...] como todas as outras formas de memórias automáticas aparecidas na história, a memória eletrônica não é senão um auxiliar, um servidor da memória e do espírito humano" (LE GOFF, 2003, p. 463 , grifo nosso). 
Lévy (1997) assinala que novas maneiras de conviver estão sendo elaboradas no mundo das telecomunicações e da informática. As relações entre os homens, o trabalho e a própria inteligência dependem de uma metamorfose incessante de dispositivos informacionais de todos os tipos. Por conseguinte, "não se pode mais conceber a pesquisa científica sem uma aparelhagem complexa que redistribui as antigas divisões entre experiência e teoria. Emerge, nesse final do século XX, "um conhecimento por simulação que os epistemologistas ainda não inventariaram" (1997, p. 7, grifos do autor).

Lévy lamenta a aversão e o distanciamento que muitos intelectuais ainda têm com relação à técnica, um dos temas filosóficos e políticos do nosso tempo. No seu entender, as categorias usuais da filosofia do conhecimento, tais como o mito, a ciência, a teoria, a interpretação ou a objetividade, dependem intimamente do uso histórico, datado e localizado de certas tecnologias individuais. Daí defender que "a técnica e as tecnologias intelectuais em particular têm muitas coisas para ensinar aos filósofos sobre filosofias e aos historiadores sobre história" (LÉVY, 1997, p. 11).

O pensamento individual, as instituições sociais e as técnicas de comunicação articulam-se para compor "coletivos pensantes homens-coisas", transgredindo as fronteiras tradicionais das espécies e reinos. Esses elementos formam um "coletivo dinâmico povoado por singularidades atuantes e subjetividades mutantes", que Lévy denomina de "ecologia cognitiva" (1997, p. 11).

O Portal da Memória se insere no campo dessas discussões teóricas traçadas por Benjamin, Le Goff e Lévy. Ele se enquadra na cultura da atualidade "intimamente ligada à ideia de interatividade, de interconexão, de inter-relação entre homens, informações e imagens dos mais variados gêneros" (COSTA, 2008, p. 8). Nasce com um objetivo bem definido: mostrar à geração do presente e à do futuro um passado institucional glorioso, imaculado, reforçado nas falas dos entrevistados e nas mensagens expostas nesse arquivo. Documentos que antes não tinham uma pretensão clara de criar uma imagem institucional, tornam-se "provas" do êxito dessa instituição. Para tanto, seus idealizadores selecionaram imagens, relatos, recortes de jornal, dentre outros registros, para apresentar ao público e, assim, consolidar uma memória que não limite ao campo individual, mas também ao coletivo. 
Nesse aspecto, é possível considerar esse Portal como um "lugar de memória" definido pelo historiador francês Pierre Nora, como:

[...] lugares, com efeito nos três sentidos da palavra, material, simbólico e funcional, simultaneamente, somente em graus diversos. Mesmo um lugar de aparência puramente material, como um depósito de arquivos, só é lugar de memória se a imaginação o investe de aura simbólica. Mesmo um lugar puramente funcional, como um manual de aula, um testamento, uma associação de antigos combatentes, só entra na categoria se for objeto de um ritual. Mesmo um minuto de silêncio, que parece o extremo de uma significação simbólica, é ao mesmo tempo o recorte material de uma unidade temporal e serve, periodicamente, para uma chamada concentrada da lembrança. Os três aspectos coexistem sempre. (NORA, 1993, p. 21-22).

Os lugares de memória estariam nas fronteiras dessas vivências. A reflexão de Nora se inicia com a expressão "aceleração da história", que é relacionada ao atual contexto de mundialização em que nos encontramos, cujas transformações incessantes e as suas decorrências, levam-nos a sentir cada vez mais a ameaça do esquecimento e, por conseguinte, pretendemos aprisionar o que sobrou do passado. Por isso, "os lugares de memória são, antes de tudo, restos", diz esse historiador (1993, p. 12). Daí a obsessão que temos hoje pelo registro, pelos traços e pelos arquivos.

Museus, arquivos, cemitérios e coleções, festas, aniversários, tratados, processos verbais, monumentos, santuários, associações, são os marcos testemunhais de uma outra era, das ilusões de eternidade. Daí o aspecto nostálgico desses empreendimentos de piedade, patéticos e glaciais. São os rituais de uma sociedade sem ritual; sacralizações passageiras numa sociedade que dessacraliza; fidelidades particulares de uma sociedade que aplaina os particularismos; diferenciações efetivas numa sociedade que nivela por princípio; sinais de reconhecimento e de pertencimento de grupo numa sociedade que só tende a reconhecer indivíduos iguais e idênticos. (NORA, 1993, p. 13).

São lugares onde a memória se cristaliza e se refugia. Eles se originam e vivem do sentimento que não existe memória espontânea e, por isso, "é preciso criar arquivos, é preciso manter aniversários, organizar celebrações, pronunciar elogios fúnebres, notariar atas, porque estas operações não são naturais", diz Nora (1993, p. 13). Para ele, caso vivêssemos as lembranças que esses lugares envolvem, eles seriam inúteis e, portanto, não seriam construídos. 
Ciavatta (2012, p. 96) também faz alusão à escola como um lugar de memória:

Por ser um espaço ocupado pela infância e a juventude, cujo sentimento do passado é quase inexistente, a escola [...], parece ser um lugar de memória ainda mais esmaecido. No entanto, esse sentimento aflora com o passar do tempo e até a vivência com os colegas de infância e de juventude tornam-se, mais tarde, densos "lugares de memória", contribuindo para a construção de uma identidade singular e, ao mesmo tempo, coletiva, como pertencimento a um tempo, a um grupo com as marcas desse tempo. (CIAVATTA, 2012, p. 96)

Podemos considerar que o uso, em larga escala, das novas tecnologias da informação tem permitido a emergência de uma nova versão dos lugares de memória, propiciada, dentre outros fatores, pela digitalização de imagens e pela enorme, ou infinita, capacidade de armazenamento de dados que essas novas máquinas possuem.

Face ao exposto, podemos afirmar que o IFRN, da mesma forma que outras instituições escolares, "produz memórias ou imaginários. Mobiliza ou desmobiliza grupos de pessoas e famílias; assinala sua presença em comemorações, torna-se notícia na mídia". Logo, não é apenas um prédio que agrupa sujeitos para trabalharem, ensinarem, aprenderem etc. (SANFELICE, 2006, p. 25). O movimento inverso também ocorre, pois a instituição é objeto de interesses contraditórios de ordem econômica, política, ideológica, religiosa e cultural, dentre outros.

\section{Considerações finais}

Tem-se observado, nas últimas décadas, a emergência de um significativo interesse pela escola e pelo seu passado. Historiadores e investigadores da história da educação passaram a eleger o patrimônio material e a memória das instituições escolares. Conforme Mogarro (2012/2013, p. 69): “A divulgação do patrimônio educativo tem vindo a consolidar-se também com os museus virtuais, que incorporam a dimensão da formação cívica, do exercício de cidadania e contribuem para a construção de identidades individuais e coletivas"

No que tange à pesquisa no Portal da Memória, esta evidenciou a grande preocupação do IFRN em guardar memórias da Educação Profissional, reforçando uma representação de continuidade histórica e conquistas, daí a preocupação em 
destacar vitórias em jogos, construção de edifícios, atos das gestões, relatos orais e escritos de seus ex-alunos e ex-professores, dentre outros registros. No que diz respeito aos depoimentos de ex-servidores, eles são eivados de emoções e demonstram a imbricação entre as experiências dos sujeitos e a história da instituição.

O Portal da Memória, ao mesmo tempo em que representa um potencial instrumento de democratização da memória na modernidade, ao acabar com as fronteiras físicas e temporais entre os sujeitos que o acessam, é também um desafio, visto que representa um novo modo de produzir, registrar e guardar a memória no mundo contemporâneo. A partir de novos suportes, e considerando que documento tem o seu "conceito em expansão" (KARNAL; TATSCH, 2009), cabe ao historiador o desafio de compreender a relação do singular com o geral, visto que essa instituição escolar não pode ser conhecida fora de um contexto maior.

Compreendemos, com base na literatura que trata dos arquivos escolares, que as instituições de ensino, a exemplo do IFRN, devem desenvolver uma política de conservação da documentação e dos testemunhos e sensibilizar os seus atores do valor desses arquivos como patrimônio cultural, embora não sejamos ingênuos para considerar uma neutralidade na organização e seleção desses documentos. Nesse aspecto, as novas tecnologias da informação e da comunicação muito podem contribuir para o acesso e a democratização desses dados.

Para que isso ocorra, Vieira (2013) destaca a necessidade de se realizar um trabalho integrado, com a participação de pesquisadores de história da educação, de arquivistas e de profissionais da área da tecnologia que the assegure adequada gestão dessas fontes, com critérios bem definidos de guarda e descarte de documentação.

\section{Referências}

BENJAMIN, Walter. O narrador: considerações sobre a obra de Nikolai Leskov. In: Magia e técnica, arte e política: ensaios sobre literatura e história da cultura. Trad. Sérgio P. Rouanet. São Paulo: Brasiliense, 1994. p. 197-221.

BLOCH, Marc. Apologia da história ou o ofício do historiador. Rio de Janeiro: Jorge Zahar Editor, 2001.

BRASIL. Decreto n. 7.566, de 23 de setembro de 1909. Cria nas capitais dos Estados as escolas de Aprendizes Artífices, para o ensino profissional primário e gratuito. Rio de Janeiro, 1909. Legislação Federal. Disponível em: 
http://portal.mec.gov.br/setec/arquivos/pdf3/decreto_7566_1909.pdf Acesso em: 13 set. 2019.

BRASIL. Lei n. 11.892, de 29 de dezembro de 2008. Institui a Rede Federal de Educação Profissional, Científica e Tecnológica, cria os Institutos Federais de Educação, Ciência e Tecnologia, e dá outras providências. Brasília, 2008. Disponível em: http://www.planalto.gov.br/ccivil_03/_ato2007-2010/2008/lei//11892.htm Acesso em: 13 set. 2019.

CIAVATTA, Maria. A formação integrada: a escola e o trabalho como lugares de memória e identidade. In: FRIGOTTO, Gaudêncio; CIAVATTA, M., RAMOS, M. (Orgs.). Ensino Médio Integrado: concepções e contradições. 3. ed. São Paulo: Cortez, 2012. p. 83-106.

CIAVATTA, Maria. $O$ trabalho docente e os caminhos do conhecimento - a historicidade da Educação Profissional. Rio de Janeiro: Lamparina, 2015.

COSTA, Rogério da. A cultura digital. 3. ed. São Paulo: Publifolha, 2008.

CUNHA, Luiz Antônio. O ensino industrial-manufatureiro no Brasil. Revista Brasileira de Educação, Rio de Janeiro, p. 89-107, maio/jun./jul./ago. 2000.

FARIA FILHO, Luciano Mendes de; VIDAL, Diana Gonçalves. História da Educação no Brasil: a constituição histórica do campo e sua configuração atual. Educação em foco, Juiz de Fora, p. 1-20, set. 2002/fev.2003.

HALBWACHS, Maurice. A memória coletiva. São Paulo: Centauro, 2006.

JULIA, Dominique. A cultura escolar como objeto histórico. Revista Brasileira de História da Educação, Campinas, n. 1, p. 9-43, jan./jun. 2001.

KARNAL, Leandro; TATSCH, Flávia Galli. A memória evanescente. In: PINSKY, Carla Bassanezi; LUCA, Tania Regina de. (Orgs) O historiador e suas fontes. São Paulo: Contexto, 2009. p. 9-27.

LÉVY, Pierre. As tecnologias da inteligência: o futuro do pensamento na era da informática. São Paulo: Editora 34, 1997.

LE GOFF, Jacques. História e memória. 5. ed. Campinas-SP: Editora da Unicamp, 2003.

LINARES, Maria Cristina; ALDEROQUI, Silvia. El Museo de las Escuelas: una década de hacer museo. História de la Educación. Anuário, Argentina, v. 14, n. 1, set. 2013.

MAGALHÃES, Justino. Contributo para a histórica das instituições educativas entre a memória e o arquivo. Braga: Universidade do Minho, 1996.

MAGALHÃES, Justino. Tecendo nexos: história das instituições educativas. Bragança Paulista: Editora Universitária São Francisco, 2004. 
MOGARRO, Maria João. Património educativo e modelos de cultura escolar na História da Educação em Portugal. Cuestiones Pedagógicas, Sevilha, n. 22, p. 67102, 2012/2013.

NORA, Pierre. Entre memória e história: a problemática dos lugares. Projeto História, São Paulo: EDUC, n. 10, dez. 1993. p. 7-28.

NOSELLA, Paolo; BUFFA, Ester. Instituições escolares: por que e como pesquisar. 2. ed. Campinas: Alínea, 2013.

PORTAL da Memória. Disponível em: http://centenario.ifrn.edu.br/ Acesso em: 13 set. 2019.

SANFELICE, José Luís. História, instituições escolares e gestores educacionais, Revista HISTEDBR On-line, Campinas, n. especial, p. 20-27, ago. 2006. Disponível em: http://www.histedbr.fe.unicamp.br/revista/edicoes/22e/art4_22e.pdf Acesso em: 14 set. 2019.

SANTOS, Rosemary Santos; SANTOS, Edméa Oliveira. Revista Eletrônica Pesquiseduca, Santos, v. 4, n. 7, p. 159-183, jan.-jul. 2012.

SAVIANI, Dermeval. Instituições escolares no Brasil: conceito e reconstrução histórica. In: NASCIMENTO, Maria Isabel M. et al. (Orgs.) Instituições escolares no Brasil: conceito e reconstrução histórica. Campinas: Autores Associados; Sorocaba: UNISO; Ponta Grossa: UEPG, 2007. p. 3-27.

SAVIANI, Dermeval. Instituições de memória e organização de acervos para a história das instituições escolares. In: SILVA, João Carlos da et al. (Orgs.) História da educação: arquivos, instituições escolares e memória histórica. Campinas: Alínea, 2013. p. 13-31.

SILVA, João Carlos da et al. (Orgs.) História da educação: arquivos, instituições escolares e memória histórica. Campinas: Alínea, 2013.

VIEIRA, Alboni Marisa D. P. Instituições escolares: memória, fontes, arquivos e novas tecnologias. In: SILVA, João Carlos da et al. (Orgs.) História da educação: arquivos, instituições escolares e memória histórica. Campinas: Alínea, 2013. p. 65-78. 